\title{
The use of recombinant fish parvalbumin Gad c 1 in the characterisation of fish allergic patients
}

\author{
Fátima Cabral Duarte ${ }^{1 *}$, Ana Célia Costa ${ }^{1}$, Manuel Augusto Pereira Barbosa ${ }^{1}$, Maria Conceição Pereira Santos ${ }^{2}$ \\ From Food Allergy and Anaphylaxis Meeting 2014 \\ Dublin, Ireland. 9-11 October 2014
}

\section{Background}

IgE mediated allergy to fish is a cause of severe anaphylatic reactions. Parvalbumins are considered major fish allergens and also responsible for cross-reactivity.

\section{Objective}

Evaluation of tolerance acquisition using the recombinant fish parvalbumin ( $\mathrm{Gad} \mathrm{c} \mathrm{1)}$ in a group of fish allergic patients (pts).

\section{Material and methods}

We selected 55 pts (34M, 21F; average age:7.4 years). All had fish allergy, characterized by positive clinical history, skin-prick tests and serum specific IgE to several fish and Gad c 1 (UniCap ${ }^{\circledR}$, Thermo-Fisher). Oral food challenge was performed to evaluate fish tolerance acquisition. Statistical analysis was performed using GraphPad Prisma version 5.0 (GraphPad Software Inc, SD). Two groups were compared using a paired t test Wilcoxon. P values $<0.05$ were considered significant.

\section{Results}

The 55 fish allergic pts had clinical symptoms for more than one fish species: 43 (78\%) pts had skin manifestations, $12(22 \%)$ anaphylaxis, $8(15 \%)$ respiratory and $9(16 \%)$ gastrointestinal symptoms. Pts who suffered anaphylaxis had lower Gad c 1 average values $(31 \mathrm{KU} / \mathrm{L})$ than the others (76.7 KU/L); $p=0.15$. 38/55 (69\%) pts were intolerant and $17 / 55$ (31\%) pts tolerated at least one fish species. Gad c 1 average values were significantly higher $(21.6 \mathrm{KU} / \mathrm{L})$ in the intolerant group than in the partially tolerant group ( 2.7 $\mathrm{KU} / \mathrm{L}) ; p=0.009$. 24/38 pts were followed for at least one year, on average 3.7 years. 14/24 pts developed fish tolerance to at least one fish species-Group I (10M, 4F; average age 7 years) and 10/24 were intolerant-Group II (6M, 4F;

${ }^{1}$ Immunoallergology Department, Hospital de Santa Maria, Lisbon, Portugal Full list of author information is available at the end of the article average age 7 years). Group I showed lower average values (4.6 KU/L) of Gad c 1 than the Group II $(25.1 \mathrm{KU} / \mathrm{L})$; $p=0.0001$.

\section{Conclusions}

Lower Gad c 1 values seem to be an important predictive parameter in fish tolerance acquisition but not in predicting clinical symptoms' severity and might be considered a useful tool in the follow-up of fish allergic patients.

\section{Authors' details}

${ }^{1}$ Immunoallergology Department, Hospital de Santa Maria, Lisbon, Portugal. ${ }^{2}$ Clinical Immunology Unit, Instituto de Medicina Molecular, Faculdade de

Medicina de Lisboa, Lisbon, Portugal.

Published: 30 March 2015

doi:10.1186/2045-7022-5-S3-P22

Cite this article as: Cabral Duarte et al:: The use of recombinant fish parvalbumin Gad c 1 in the characterisation of fish allergic patients. Clinical and Translational Allergy 2015 5(Suppl 3):P22.

Submit your next manuscript to BioMed Central and take full advantage of:

- Convenient online submission

- Thorough peer review

- No space constraints or color figure charges

- Immediate publication on acceptance

- Inclusion in PubMed, CAS, Scopus and Google Scholar

- Research which is freely available for redistribution 